\title{
CAUSES AND CONSEQUENCES OF TEENAGE PREGNANCY IN BORNO STATE OF NIGERIA: IMPLICATIONS FOR COUNSELLING
}

\section{ALHAJI MUSTAPHA UMARA}

Department of Education, University of Maiduguri, Nigeria.

\section{NGOHI, BUKAR UMAR}

College of Legal \& Islamic Studies, Maiduguri, Nigeria.

\begin{abstract}
The study was a survey that investigated the causes and consequences of teenage pregnancy in Borno State, Nigeria. A total of 1,500 parents participated in the study from 15 high, medium and low density residential areas of Maiduguri Metropolis. The sample consisted of 874 (58.27\%) males and 626 (41.73\%) females. A questionnaire tagged Causes and Consequences of Teenage Pregnancy (CACOTEP) developed by the researchers was used to collect data for the study. Data collected were analyzed using descriptive statistical techniques of frequency counts, percentages and rank ordering. Chi-square $\left(x^{2}\right)$ was also used to test the null-hypothesis at 0.05 alpha level of significance. Results of the study indicated poverty, experimenting sex, early sexual debut, single parenting, broken homes, street hawking, lack of moral education, rape, peer influence and exposure to pornographic films as some of the causes of teenage pregnancy while abortion, expulsion from school, loss of self-esteem, risk of contracting HIV/AIDS, VVF, $R V F$, premature labour/birth and premature death were some of the consequences of teenage pregnancy in Borno State, Nigeria. Significant relationship does not exist between gender and teenage pregnancy as revealed by the study. Sex education/reproductive health education, moral education, discouraging street hawking and inculcating positive social values by counsellors, parents, community and religious leaders using both print and electronic (visual and blind) media, hand bills and staging dramas on the negativities of teenage pregnancy were some of the implications for counselling proffered. It is recommended that the Borno State government should stop girls from hawking, introduce females' entrepreneurship centers and build counselling centers to engage services of certified counsellors with a view to halting the menace through moral/religious counselling.
\end{abstract}

Keywords: Teenage Pregnancy, Causes, Consequences, Implications for Counselling

\section{Introduction}

Teenage pregnancy has far reaching effects on the teenage mothers and their babies. Teenage pregnancy is the pregnancy that occurs when a girl is below the age of 18 years and, in most instances, she is out of wedlock, unplanned and unwanted. Such pregnancies usually occur as a result of inadequate information about reproductive health, use of contraceptives and risks of pregnancy while sometimes they occur within the context of early marriage (Sambo, 2009). However, Hussaini (2006) considered teenagers as children who have reached the age of 13 to 19 years, the period in which the capacity for reproduction is attained and marked by changes in both primary and secondary sexual characteristics which start from menarche in girls, development of body contours and emergence of pigmented pubic hairs .Teenage pregnancy, according to the Federal Ministry of Health (FMH, 2001), is the pregnancy in a female under the age of 20. A pregnancy can take place as early as two weeks before menarche (first menstrual period) which signals the probability for fertility but usually occurs after menarche. In healthy, well nourished girls, menarche normally takes place around the age of 12 to 13 . Whether the onset of biological fertility will result in a pregnancy depends on a number of personal and social factors. Pregnancy of teenage girls rates vary between countries because of differences in levels of sexual activities, the sex education provided and access to affordable contraceptive options. Worldwide teenage pregnancy rates range from 143 per 1000 in some sub-Saharan countries to 2.9 per 1000 in South Korea (Bankole \& Musa, 2007). 
Although teenage parents often don't have the financial resources to cater for their offsprings, Sambo (2009) posited that declining age of menarche, early sexual debut, early marriage, pressure to have children, sexual coercion and rape, socio-economic factors such as economic hardship, sexual experimentation, lack of access to reproductive health information and services, unprotected sexual intercourse, sexual exploitation of girls by older men for financial gains, sexual exploitation of girls by male relations/acquaintances and risky behaviors such as substance abuse are the principal factors contributing to teenage pregnancy in Nigeria. However, Bankole \& Musa (2007), Kabir (2008), Tukur \& Bello (2009) and Kayode (2011) identified financial problem street hawking, rape, poor/lack of moral education, single parenting, breaken homes, ignorance, peer influence, exposure to pornographic films and glamour of the city life, as the factors contributing to teenage pregnancy.

Teenage pregnancy has been found to have negative long-lasting health, social and economic consequences on the life of the teenage parents. Teenage mothers face the risk of increased health problems both for themselves and for their babies. Problems to the babies include pre-maturity, stillbirth and low birth weights. Early childbearing may result in Vesico Vaginal Fistula (VVF) and Recto Vaginal Fistula (RVF). This is a hole caused by weakening of the wall between the bladder/rectum and the vagina, leading to uncontrolled leakage of urine or faeces. Girls affected by VVF/RVF are unfortunately rejected by their husbands and relatives (Bankole \& Musa, 2007; Sambo, 2009 and Tukur \& Bello 2009). Sambo (2009), for example, identified three major consequences of teenage pregnancy as abortion, school dropout and illegal marriage resulting in broken homes. Other consequences identified by Abiso (2000) include pathological consequences such as HIV/AIDS infection, premature labour and delivery, anemia, risks associated with abortion, complications during labour and delivery, hypertensive diseases of pregnancy such as pre-eclampsia, puerperal sepsis, post-partum depression, obstructed labour, lack of appropriate antenatal care and other long term health effects.

The socio-economic consequences of teenage pregnancy identified by Kayode (2011) include dependent of the teenage mother on parent for basic needs, rejection of the teenage mother by parents, relatives and friends. A teenage mother with little or no training is limited to low paying jobs with low socio-economic status. Some of the consequences that can be attributed to the child, as identified by Sambo (2009) include, low birth weights resulting in respiratory infections and failure to thrive, higher risk of dying in infancy, feeling rejected and having emotional problems, stigmatization, poverty and lack of stability leading to vicious cycle of the children also becoming teenage parents and inadequate nutrition due to poor breastfeeding. Abiso (2000) and Kayode (2011) considered family sex education, use of contraceptives, inculcating positive values about boy/girl relationships and total abstinence from pre-marital sex as the preventive measures against the menace of teenage pregnancy. It is against this background that this study sought to identify the perceived causes and consequences of teenage pregnancy in Borno State, Nigeria and proffer some counselling implications.

\section{Statement of the Problem}

Sexual exploitation of children has been on the increase as insufficient knowledge about their sexuality has resulted in teenage girls with unwanted pregnancies. No less than 40 percent of maternal deaths in the nation each year, which may be put at one thousand out of every hundred thousand live births, seem to be associated with teenage pregnancy and 
complications of abortion. Although one's philosophy, experience, exposure to the raw edges of human existence, religious training, attitudes towards life and family and their values and the moral standard one establishes and observes are all likely to influence and color one's thinking and conclusion about teenage pregnancy. The issue of teenage pregnancy is a very sensitive one in, especially, Borno State coupled with the contemporary socio-economic realities. The results of teenage pregnancy have resulted in children dropping out of school, early marriages and, at worst, health risks of contracting HIV/AIDS, VVF and RVF. Lack of education due to unwanted teenage pregnancy has a multiplier effect in terms of negative consequences ranging from lack of selfactualization, lack of livelihood to destitution and a high probability that the vicious cycle could become hereditary. This is a worrisome trend and has been a source of concern for the government, medical practitioners, women groups, educationists, researchers, parents, lawyers, non-governmental organizations and other stakeholders of women reproductive health. It was therefore the focus of this study to investigate the causes and effects of teenage pregnancy in Borno State, Nigeria with a view to proffering some counselling implications.

\section{Objectives of the Study}

The objectives of this study were to identify:

1. Causes of teenage pregnancy in Borno State, Nigeria

2. Consequences of teenage pregnancy in Borno State, Nigeria

3. Determine if significant relationship existed between poverty and teenage pregnancy in Borno State, Nigeria

\section{Research Questions}

The following research questions were answered in the study:

1. What are the causes of teenage pregnancy in Borno State, Nigeria?

2. What are the causes of teenage pregnancy in Borno State by gender?

3. What are the consequences of teenage pregnancy in Borno State, Nigeria?

\section{Hypothesis}

The following null-hypothesis was tested in the study:

$\mathrm{Ho}_{1}$ : There is no significant relationship between poverty and teenage pregnancy in Borno State, Nigeria.

\section{Methodology}

The study was an exploratory survey research designed to identify the causes and consequences of teenage pregnancy in Borno State and to determine if there existed any relationship between poverty and teenage pregnancy in the study area. The study used a sample of 1,500 parents made up of 874(58.27\%) males and 626(41.73\%) females selected from 15 wards (residential areas) in the metropolis. Specifically, 5 wards were selected from each of the high, medium and low density residential areas. The high density residential areas included Adamkolo, Shehuri-North, Shehuri-South, Kaliari and 
Mafoni wards, the medium density residential areas were Ibrahim Taiwo Housing Estate, Old Government Residential Area, Pampamari, Kumshe and Gwange 1V wards while 202, 303, 505, 707 and 1000 Housing Estates were the low density residential areas considered for the study.

A questionnaire tagged Causes and Consequences of Teenage Pregnancy (CACOTEP) developed by the researchers was the instrument used to collect data for the study. The Instrument was divided into three sections of A, B and C. Section A elicited information on biodata of the respondents such as age, sex, marital status, location, occupation, etc. Statements on sections B and C obtained data on the causes and effects of teenage pregnancy in Borno State, Nigeria. The response system for the 36 items in sections A and B of the instrument was based on yes or no. The face and content validity as well as reliability of the test instrument were established. The face and content validity were established by giving draft copies of the questionnaire to experts in Educational Psychology, Measurement and Evaluation and Guidance and Counselling of not less than the rank of a Senior Lecturer who assessed the adequacy/suitability or otherwise of the constituent items of the instrument. The questionnaire was modified by integrating the objective corrections and suggestions of these experts. The reliability was established through a test-retest reliability method. The correlation coefficient obtained was 0.66 which was considered adequate and adjudged appropriate for the study.

The test instrument was administered on the subjects by the researchers with the assistance of three trained research assistants who were post-graduate students of Educational Psychology and Guidance and Counselling of the University of Maiduguri. The CACOTEP were administered on face-to-face basis over a period of four weeks. The subjects were assured of confidentiality over the information they provided and all copies of the instrument were retrieved which ensured $100 \%$ collection.

\section{Data Analysis}

To analyze the data collected, descriptive statistical techniques of frequency counts and percentages were used to answerer the research questions. The responses were further ranked to give a pictorial view of the respondents rating of each item on the interview schedules. The hypothesis was tested using Chi-square $\left(\mathrm{x}^{2}\right)$. The results were presented in Tables 1-3.

\section{Results}

Research Question One: What are the causes of teenage pregnancy in Borno State, Nigeria?

Table 1: $\quad$ Causes of Teenage Pregnancy in Borno State, Nigeria ( $N=1500)$

\begin{tabular}{llll}
\hline Causes & Frequency & Percentage & Rank \\
\hline Poverty & 116 & 7.73 & $1^{\text {st }}$ \\
Experimenting sex & 114 & 7.60 & $2^{\text {nd }}$ \\
Single parenting & 107 & 7.13 & $3^{\text {rd }}$ \\
Broken homes & 104 & 6.93 & $4^{\text {th }}$ \\
Peer influence & 100 & 6.70 & $5^{\text {th }}$ \\
Early marriage & 96 & 6.40 & $6^{\text {th }}$ \\
Street hawking & 92 & 6.13 & $7^{\text {th }}$ \\
\hline
\end{tabular}




\begin{tabular}{llll} 
Desire to pass exams & 90 & 6.00 & $8^{\text {th }}$ \\
Ignorance of the use of contraceptives & 88 & 5.87 & $9^{\text {th }}$ \\
Lack of sex education & 86 & 5.72 & $10^{\text {th }}$ \\
Early sexual debut & 83 & 5.53 & $11^{\text {th }}$ \\
Declining age of menarche & 81 & 5.40 & $12^{\text {th }}$ \\
Poor child rearing practices & 79 & 5.30 & $13^{\text {th }}$ \\
Substance abuse & 77 & 5.13 & $14^{\text {th }}$ \\
Sexual exploitation by relatives/acquaintances & 59 & 3.90 & $15^{\text {th }}$ \\
Rape & 54 & 3.60 & $16^{\text {th }}$ \\
Lack of moral education & 42 & 2.80 & $17^{\text {th }}$ \\
Exposure to pornographic films & 32 & 2.13 & $18^{\text {th }}$ \\
\hline
\end{tabular}

Table 1 above indicates that poverty, experimenting sex, single parenting, broken homes and peer influence ranked the five major causes of teenage pregnancy perceived by parents in Borno State, Nigeria while substance abuse, sexual exploitation by relatives/acquaintances, rape, lack of moral education and exposure to pornographic films ranked the five minor causes of teenage pregnancy perceived by the respondents in the study area.

Research Question Two: What are the causes of teenage pregnancy in Borno State by gender?

Table 2: $\quad$ Causes of Teenage Pregnancy in Borno State, Nigeria by Gender

\begin{tabular}{l|llll}
\hline \multirow{2}{*}{ Causes } & Responses & & \\
\cline { 2 - 5 } & Male & Rank & Female & $\begin{array}{l}\text { Ran } \\
\mathrm{k}\end{array}$ \\
\hline Poverty & $84(5.60)$ & $1^{\text {st }}$ & $48(3.20)$ & $1^{\text {st }}$ \\
Experimenting sex & $78(5.20)$ & $2^{\text {nd }}$ & $19(1.27)$ & $16^{\text {th }}$ \\
Single parenting & $77(5.13)$ & $3^{\text {rd }}$ & $32(2.13)$ & $12^{\text {th }}$ \\
Broken homes & $74(4.93)$ & $4^{\text {th }}$ & $32(2.13)$ & $12^{\text {th }}$ \\
Peer influence & $72(4.80)$ & $5^{\text {th }}$ & $48(3.20)$ & $1^{\text {st }}$ \\
Early marriage & $66(4.40)$ & $6^{\text {th }}$ & $19(1.27)$ & $16^{\text {th }}$ \\
Street hawking & $64(4.27)$ & $7^{\text {th }}$ & $10(0.67)$ & $18^{\text {th }}$ \\
Desire to pass exams & $59(3.93)$ & $8^{\text {th }}$ & $35(2.33)$ & $9^{\text {th }}$ \\
Ignorance of the use of contraceptives & $55(3.67)$ & $9^{\text {th }}$ & $45(3.00)$ & $3^{\text {rd }}$ \\
Lack of sex education & $50(3.33)$ & $10^{\text {th }}$ & $45(3.00)$ & $3^{\text {rd }}$ \\
Early sexual debut & $44(2.93)$ & $11^{\text {th }}$ & $35(2.33)$ & $9^{\text {th }}$ \\
Declining age of menarche & $43(2.87)$ & $12^{\text {th }}$ & $35(2.33)$ & $9^{\text {th }}$ \\
Poor child rearing practices & $30(2.00)$ & $13^{\text {th }}$ & $32(2.13)$ & $12^{\text {th }}$ \\
Substance abuse & $29(1.93)$ & $14^{\text {th }}$ & $37(2.47)$ & $8^{\text {th }}$ \\
Sexual exploitation by & $25(1.67)$ & $15^{\text {th }}$ & $43(2.87)$ & $5^{\text {th }}$ \\
relatives/acquaintances & & & & \\
Rape & $10(0.67)$ & $16^{\text {th }}$ & $40(2.67)$ & $6^{\text {th }}$ \\
Lack of moral education & $08(0.53)$ & $17^{\text {th }}$ & $32(2.13)$ & $12^{\text {th }}$ \\
Exposure to pornographic films & $06(0.40)$ & $18^{\text {th }}$ & $39(2.60)$ & $7^{\text {th }}$ \\
\hline Total & $874(58.27)$ & & $626(41.73)$ & \\
\hline Note All figurs in brackets & & & \\
\hline
\end{tabular}

Note: All figures in brackets are percentages of the raw scores.

Table 2 above reveals causes of teenage pregnancy perceived by male and female parents in Borno State, Nigeria. The Table (Table 2) shows that male parents ranked poverty, 
experimenting sex, single parenting, broken homes and peer influence as the top five causes of teenage pregnancy while their female counterparts ranked poverty, peer influence, ignorance of the use of contraceptives, lack of sex education and sexual exploitation by relatives/acquaintances as the top five causes of teenage pregnancy in the study area.

Ho1: There is no significant relationship between poverty and teenage pregnancy in Borno State, Nigeria.

Table 3: Chi-square $\left(x^{2}\right)$ relationship between poverty and teenage pregnancy in Borno State, Nigeria

\begin{tabular}{lllllll}
\hline Variable & $\mathrm{N}$ & $\mathrm{X}$ & $\mathrm{Df}$ & $\mathrm{C}$ & $\mathrm{P}$ & $\mathrm{D}$ \\
\hline Male & 874 & 112 & 2 & 0.324 & 1.931 & Accepted \\
Female & 626 & 74.81 & & & & \\
\hline
\end{tabular}

$\mathrm{Df}=$ Degree of freedom

$\mathrm{C}=$ Obtained contingency coefficient

$\mathrm{P}=$ Critical value of contingency coefficient

$\mathrm{D}=$ Decision

It is evident from Table 3 above that there is no significant relationship between poverty and teenage pregnancy in Borno State, Nigeria. This is because the Chi-square value of 1.931 and obtained contingency coefficient of 0.324 is not significant at 0.05 level. Therefore, the null-hypothesis was accepted.

Research Question Three: What are the consequences of teenage pregnancy in Borno State, Nigeria?

Table 4: $\quad$ Consequences of Teenage Pregnancy in Borno State, Nigeria $(\mathbf{N}=1500)$

\begin{tabular}{llll}
\hline Consequences & Frequency & Percentage & Rank \\
\hline Abortion & 120 & 8.0 & $1^{\text {st }}$ \\
Expulsion from school & 111 & 7.4 & $2^{\text {nd }}$ \\
Risk of contracting HIV/AIDS & 110 & 7.3 & $3^{\text {rd }}$ \\
Loss of self-esteem & 110 & 7.3 & $3^{\text {rd }}$ \\
Premature death & 98 & 6.5 & $5^{\text {th }}$ \\
Premature labour/delivery & 90 & 6.0 & $6^{\text {th }}$ \\
Risk of contracting eclampsia/anemia & 90 & 6.0 & $6^{\text {th }}$ \\
Risk of contracting VVF/RVF & 85 & 5.7 & $8^{\text {th }}$ \\
Puerperal sepsis/post-partum depression & 83 & 5.5 & $9^{\text {th }}$ \\
Gossip from schoolmates/peers & 80 & 5.3 & $10^{\text {th }}$ \\
Illegal marriage & 80 & 5.3 & $10^{\text {th }}$ \\
Embarrassment and self-hatred & 79 & 5.2 & $12^{\text {th }}$ \\
Pain of being exploited & 77 & 5.1 & $13^{\text {th }}$ \\
Inability to take care of herself and the baby & 75 & 5.0 & $14^{\text {th }}$ \\
Rejection by family /relations & 66 & 4.4 & $15^{\text {th }}$ \\
Higher risk of infant mortality & 63 & 4.2 & $16^{\text {th }}$ \\
Stigmatization & 60 & 4.0 & $17^{\text {th }}$ \\
Poor nutrition of the teenage mother/ baby & 23 & 1.5 & $18^{\text {th }}$ \\
\hline
\end{tabular}


Table 4 above shows that abortion, expulsion from school, risk of contracting HIV/AIDS, loss of self-esteem, premature death, premature labour/delivery and the risk of contracting eclampsia/anemia ranked the seven top consequences of teenage pregnancy perceived by parents in Borno State while embarrassment and self-hatred, pain of being exploited, inability to take care of herself and the baby, rejection by family/relations, higher risk of infant mortality, stigmatization and poor nutrition of the teenage mother/baby ranked the seven least consequences of teenage pregnancy perceived by the respondents in Borno State, Nigeria.

\section{Discussion}

This study identified 18 causes of teenage pregnancy in Borno State, Nigeria. The major causes identified in descending order were poverty, experimenting sex, single parenting, broken homes and peer influence. Others included early marriage, street hawking, desire to pass exams, ignorance of the use of contraceptives, lack of sex education, early sexual debut, declining age of menarche and poor child rearing practices while substance abuse, sexual exploitation by relatives/acquaintances, rape, lack of moral education and exposure to pornographic films were the minor causes.

The findings of this study corroborate the earlier findings of Waite \& Gallagher (2000), Bankole \& Musa (2007), Kabir (2008) Tukur \& Bello (2009) and Kayode (2011). Waite \& Gallagher (2000) for example, expressed that poverty, ignorance of the use of contraceptives, broken homes, poor child rearing practices and children of divorced parents are far more likely to engage in pre-marital sex and bear children out of wedlock. Others included the desire to pass exams, influence of peers, experimenting sex and declining age of menarche. The tendency was thus high for the children of the poor, broken homes and divorced parents who experienced poor child rearing practices, lack moral education, lack sex education especially the use of contraceptives and engaged in street hawking which would further expose them to sexual exploitation for financial gains. Hence, parents were expected to fend for their wards, educate them, provide love, security, respect, dignity, care, concern and grow up to be disciplined.

Similar to the findings of this study especially on pornographic films as a factor of teenage pregnancy in Borno State, Abiso (2000) expressed that print and electronic media (Television, Papers and Magazines) tremendously inculcate foreign culture into the youths which they subsequently emulate and gradually implement most of what they watched, read or heard about. For instance, most films teenagers enjoy watching (nude, sex treks and pornography) are immoral and can lead them to experimenting sex resulting in teenage pregnancy.

On the consequences of teenage pregnancy in Borno State, Nigeria identified by the study in descending order are abortion, expulsion from school, risk of contracting HIV/AID, loss of self-esteem, premature death, premature labour/delivery, risk of contracting eclampsia/anemia, VVF/RVF and puerperal sepsis/post-partum depression. Others include gossip from schoolmates/peers, illegal marriage, embarrassment and self-hatred, pain of being exploited, inability to take care of herself and the baby, rejection by family/relations, higher risk of infant mortality, stigmatization and poor nutrition of the teenage mother and the baby. This agreed with the findings of Abiso (2000), Otoide, Orunsaye \& Okonofiya (2001), Tukur \& Bello (2009), Sambo (2009) and Kayode (2011). 
Sambo (2009) for example, expressed that consequences of teenage pregnancy are obviously categorized into physical, psychological/emotional and socio-economic.

Some of the physical consequences expressed by Kayode (2011) included antenatal complications due to premature labour and delivery, hypertensive diseases of pregnancy such as pre-eclampsia, anemia, primigravida, poor health condition of the teenage mother and risk associated with obstructed labour, cases of VVF/RVF and post-partum depression. Rejection of the teenage mother by parents, relatives and friends, financial dependency and little or no pay job constituted the socio-economic consequences while regret, shame, having to put up with a lot of ridicule and gossip from schoolmates/peers, embarrassment, self doubts leading to loss of self-esteem, fear of the immediate and what the future may be, expulsion from school and having to marry someone she may not truly love constitute some of the psychological/emotional consequences of teenage pregnancy. In consonance with the findings of this study, Gilda \& Akiliri (1997) and Tukur \& Bello (2009) reported inadequate nutrition due to poor breastfeeding, higher risk of dying in infancy, low birth weight resulting in respiratory infections and lack of stability leading to the vicious cycle of the children also becoming teenage parents as some of the consequences on the child.

This study also tested a null-hypothesis using Chi-square $\left(\mathrm{x}^{2}\right)$ statistics which was estimated at 0.05 level of significance. The result showed that no significant relationship exist between poverty and teenage pregnancy in Borno State. The lack of relationship may not be unconnected with the belief that poverty is one of the factors that negatively influences adolescents' attitude. This might probably be one of the causes of teenagers engaging in pre-marital sex. It could also be explained by the impression that is deeply rooted in the society that lack of moral education and street hawking can lead to immorality resulting in teenage pregnancy which is usually unplanned and unwanted. This result affirmed the findings of Bankole \& Musa (2007) who concluded that poverty, poor parental upbringing and single parenting have significant influence on the behavior of a child.

\section{Implications for Counselling}

Based on findings of this study, there was a serious need for earlier re-orientation of the teenagers towards positive social values through guidance and counselling. Teenagers should be informed through self-awareness to resist pre-marital sex. Counsellors should imbibe in the teenagers the fact that affection can be shown in ways other than sexual intercourse. As rightly reported by Mburza (2008), they should be given the opportunity to discuss the reasons (single parenting, risk of contracting HIV/AIDS, VVF, RVF) for delaying sexual intercourse and learn how to resist pressure for unwanted sex. It is believed that if teenagers have a collective responsibility to confront the menace of unwanted pregnancy, the evil of teenage pregnancy will be recognized and the appreciation of moral education will evolve. Counsellors should in collaboration with parents and other stakeholders enlighten the teenagers on sex education/reproductive health education with a view to declining any form of pre-marital sex.

Parents should interact with their family members such that parents and children can communicate freely and respect each other's opinion. Positive information should be freely disseminated for family cohesion with a view to preventing teenagers from getting wrong information from their peers. If teenagers are adequately informed of the attendant 
consequences of unwanted pregnancy to the teenage mother, her parents and the wider society, there will be a high tendency of them to make good decisions at all times. Teenagers should not be engaged in street hawking or be left idle either at home or in school but be occupied academically, spiritually and recreationally so as to make good use of their time because the devil finds work for the idle mind. Parents should also educate their wards on the consequences of teenage pregnancy and provide them with the necessary comfort they need. This is necessary because, as observed by Ugwuegbulam \& Okafor (2001), most families in Nigeria do not have enough money with which to provide for themselves basic things for survival. Poverty breeds hunger and starvation which ultimately predisposes members of such families, especially the teenagers to engage in illegal and/or illicit means of survival leading the unwanted pregnancies.

Counsellors should in collaboration with parents, religious and community leaders inculcate community, moral and positive national values into the teenagers. Counsellors should in conjunction with educationists, Ministries of Education, youths and social development, non-governmental organizations, philanthropists and other spirited individuals organize public lectures, seminars, symposiums, workshops, talkshops and conferences on the detrimental effects of teenage pregnancies and other delinquent behaviors to parents and other stakeholders. Government at all levels should curtail if not completely stop/ban the advertisement and importation of aggressive and nude films. Counsellors should in collaboration with the mass media embark on massive enlightenment campaigns through the print and electronic media (radio, television, magazines and Newspapers), handbills, posters and organizing youths to display cards, stage dramas, radio jingles and phone-in-calls on the negativities of teenage pregnancies with a view to totally curb a such menace.

\section{Conclusion}

Based on the findings of this study, it was concluded that:

1. Poverty, experimenting sex, single parenting, broken homes and peer influence were the five top most causes of teenage pregnancies perceived by parents in Borno State while substance abuse, sexual exploitation by relatives/acquaintances, rape, lack of moral education and exposure to pornographic films were ranked as the lowest causes of teenage pregnancies in Borno State, Nigeria.

2. Abortion, expulsion from school, risk of contracting HIV/AIDS, loss of selfesteem, premature death, premature labour/delivery and risk of contracting eclampsia/anemia were the seven top most consequences of teenage pregnancy perceived by parents in Borno State while embarrassment and self-hatred, pain of being exploited, inability to take care of herself and the baby, rejection by family/relations, higher risk of infant mortality, stigmatization and poor nutrition of the teenage mother / baby ranked the least consequences.

3. Significant relationship does not exist between poverty and teenage pregnancies in Borno State, Nigeria.

\section{Recommendations}

Based on the findings, the following recommendations were made: 
1. There is the need for sex education at home and in schools, notwithstanding traditional and religious norms.

2. The Borno State government should build counselling centers where counsellors could be consulted for adolescent and moral counselling.

3. Parents should, in collaboration with counsellors, religious and community leaders organize conferences, seminars, workshops and talkshops to the youths on the consequences of teenage and unwanted pregnancies.

4. Community Based Organizations (CBOs), Religious Based Organizations (RBOs) and other Non-Governmental Organizations (NGOs) should organize value reorientation days and inculcate into the youths moral and other social values of the community to address declining moral/religious codes.

5. The Borno State government should in addition to establishing agencies that will assist exploited teenagers, enact legislations or enforce existing ones (laws, edicts, policies or programmes) with a view to halting the menace of teenage pregnancy.

6. The Borno State government should introduce rehabilitation and entrepreneurial skills acquisition centers/programmes for school drop outs especially the sexually exploited teenagers.

7. Counsellors should in collaboration with Ministries of Education, Youths and Sports, Social Welfare and the Media organize phone-in calls, publish hand bills, posters and stage drama on the attendant consequences of unwanted pregnancies on the teenage mothers.

\section{References}

Abiso, A. K. (2000). Legalization of abortion: Another perspective. Enugu, Temuco Publishers.

Bankole, C. L. and Musa, D. (2007). The effects of father absence on child development: A handbook of developmental psychology. Ibadan, Patrice Continental Limited.

Federal Ministry of Health (FMH, 2001). National training manual on adolescent health and development, 33-35.

Gilda, S. \& Akiliri, U. B. (1997). Unwanted pregnancy and associated factors among Nigerian women. International family planning perspectives, 32 (4): 175-184.

Hussaini, R. (2006). Reducing unwanted pregnancy in Nigeria: Research in brief. New York, Alan Gutmater.

Kabir, M. T. ( 2008). Re-orientation: A panacea for youth problems. Paper presented at a seminar organized by Youth Development Forum (YDF), Gidan Matasa, Minna, Niger State, Nigeria between $18^{\text {th }}$ and $21^{\text {st }}$ June.

Kayode, O. S. (2011). A survey of social vices in Kaduna State, Nigeria. Jos, Seeye Press, 73-77.

Mburza, A. (2008). Types and causes of delinquent behavior engaged in by adolescents in Borno State: Implications for counselling. African journal of vocational education (AJOVED). 3 (2): 99-112. 
Otoide, V. O, Orunsaye, F. \& Okonofiya, F. (2001). Why Nigerian adolescents seek abortion rather than contraception: Evidence from focused group discussion. International family planning perspectives, 27 (2): 77-81.

Sambo, S. (2009). Counselling strategies for minimizing youth and adolescent problems, Ahmadu Bello University Press Limited, Zaria, Kaduna State, Nigeria, 62-71.

Tukur, G. K. and Bello, A. W. (2009). Socio-economic impacts of teenage pregnancy among street hawkers in Gombe State, Nigeria. Paper presented at a workshop organized by MCAN, Gombe State, between $17^{\text {th }}$ and $18^{\text {th }}$ September.

Ugwuegbulam, C. N. and Okafor, H. C. (2001). Delinquency, In H. C. Okafor, C. N. Ugwuegbulam \& B. I. Nnondum (Eds). Adolescent psychology, Owerri: Joe Mankpas publishers, 131-146.

Waite, L. T. and Gallagher, M. (2000). The case for marriage, New York: Broadway Books. AW2. 